\title{
That Obscure Object of Desire: Pleasure in Painful Art
}

\author{
[Penultimate version. To appear in Suffering Art Gladly: The Paradox of Negative \\ Emotion in Art, Jerrold Levinson, ed., Palgrave Macmillan, 2013] \\ Jonathan Gilmore \\ jsg8@columbia.edu
}

EDGAR

O thou side-piercing sight!

KING LEAR

Nature's above art in that respect.... drama:

David Hume famously noted a puzzling aspect of our engagement with works of tragic

It seems an unaccountable pleasure, which the spectators of a well-written tragedy receive from sorrow, terror, anxiety, and other passions, that are in themselves disagreeable and uneasy. The more they are touched and affected, the more are they delighted with the spectacle; and as soon as the uneasy passions cease to operate, the piece is at an end. ${ }^{1}$

What is puzzling is not that works such as tragedies seem to provoke both pleasure and pain, for many nonperplexing experiences do that. Nor is it odd that feeling pain may be necessary for feeling pleasure, for many ordinary circumstances have that structure. Rather, Hume's enigma is that our pleasure seems to be internally related to our distressing feelings. Feeling such pain is not a regrettable cost, but an essential element, of the pleasure in question, without which it would not be a desirable one. One would delight in blood-red sunsets even if they were not caused, as it happens, by aerosol pollution, but one would not derive certain pleasures from tragic dramas if they did not provoke their characteristic kinds of distress. ${ }^{2}$ As Hume notes, audiences are "pleased in proportion as they are afflicted." "Y Yet how best to describe this puzzle, beyond the noncommittal sketch above, remains contentious.

On the one hand, we often pursue and take pleasure or satisfaction in works of art in ways that are ostensibly explained by their elicitation of painful, disvalued, or disagreeable feelings: sadness at the death of a novel's protagonist, fear of a movie monster, disgust for the simulated viscera of a painting, shock and trauma in a video game, cringing embarrassment for a television comedy's heedless characters, alienation in listening to punk rock, grief in listening to a threnody, discombobulation in passing through an installation, or profound boredom and acedia, as might arise in watching Andy Warhol's 8-hour-long continuous footage of the Empire State

\footnotetext{
${ }^{1}$ David Hume, “Of Tragedy," in Essays: Moral, Political, and Literary, ed. E. F. Miller (Indianapolis: Liberty, 1987), 216.

${ }^{2}$ See the April Fools Day, 2006 broadcast by NPR on the "Positive Opera Company" that installs happy endings in what are otherwise depressing productions of Don Giovanni, La Bohème, and others.
}

${ }^{3}$ Hume, 217. 
Building filmed from a static point of view.

On the other hand, our engagement with such works does not conform to the prima facie plausible assumption that we tend not, and ought not, to pursue experiences for the sake of distress, pain, annoyance, or other aversive feelings, and that when we must undergo such experiences we do not, and should not, value them for their disagreeable dimensions.

Attempts to resolve this conundrum typically introduce reasons for why, despite what seems to be our usual tendency, we may be motivated to pursue experiences of art that elicit disagreeable responses. A non-exhaustive catalog of these reasons includes, most prominently, the pleasures offered by tragedy, which may distract us from, compensate for, ${ }^{4}$ convert into a palatable form, ${ }^{5}$ or arise as a meta-response ${ }^{6}$ to the pain it causes. Other reasons include: the mere desire for affective stimulation, whether its valence is positive or negative, ${ }^{7}$ a clarification of our emotions, ${ }^{8}$ an intrinsically valuable enlightenment about the nature of suffering, ${ }^{9}$ and an opportunity to contemplate our own vulnerability to loss. ${ }^{10}$ Some of these reasons might be more plausibly seen as identifying the conditions under which we desire to experience tragedies, rather than the reasons justifying that desire. And each of these explanations may not be exclusive of one or more of the others.

When construed in those general terms, we can see how many sorts of experiences fall within the problem's scope. Hume refers to religious sermons and oratory as provoking, like tragedy, a pleasure in distress. ${ }^{11}$ We often find satisfaction in non-fiction works, e.g. of history or documentary photography, even as they provoke pity and resentment. Many people are titillated by lurid and disturbing journalism that has little cognitive or practical value. Others find the violence in bullfighting or boxing repellent but enthralling. A long-distance runner might find deep satisfaction in having exercised to the point of exhaustion. And one might, for a thrill, eat too-hot chili peppers, risk one's physical wellbeing, or imagine inordinately nauseating or frightful circumstances.

${ }^{4}$ See Nöel Carroll, The Philosophy of Horror: or, Paradoxes of the Heart (New York:

Routledge, 1990).

${ }^{5}$ Hume's solution in "On Tragedy."

${ }^{6}$ See Susan Feagin, "The Pleasures of Tragedy," American Philosophical Quarterly vol. 20 (1983): 95-104.

${ }^{7}$ Hume's interpretation of l'Abbé Dubos. Compare this to measures employed by psychologists of subjects' dispositional desires for emotionally provocative experiences: Gregory Maio and Victoria M. Esses, "The Need for Affect: Individual Differences in the Motivation to Approach or Avoid Emotions," Journal of Personality vol. 69, no. 4 (2001): 583-614.

${ }^{8}$ As proposed in interpretations of Aristotle's notion of catharsis. See Alexander Nehamas, "Pity and Fear in the Rhetoric and the Poetics," in Amelie Rorty, ed., Essays on Aristotle's Poetics (Princeton, NJ: Princeton University Press, 1992).

${ }^{9}$ See Flint Schier, "Tragedy and the Community of Sentiment," in Philosophy and Fiction: Essays in Literary Aesthetics, ed. P. Lamarque (Aberdeen: Aberdeen University Press, 1983). In some accounts, this enlightenment is identified as conducive to moral value of some sort. See Aaron Ridley, "Tragedy," in The Oxford Handbook of Aesthetics, ed. J. Levinson (Oxford: Oxford University Press, 2003); and Malcolm Budd, Values of Art (London: Penguin, 1995).

${ }^{10}$ See Samuel Johnson's "Preface to Shakespeare" (1765) in Johnson on Shakespeare, ed. Arthur Sherbo (New Haven: Yale University Press, 1968), i.77-78.

${ }^{11}$ Hume, David. A Treatise of Human Nature, ed. Selby-Bigge (Oxford: Clarendon Press, 1986), Book I, Part III, sect. IX. 
The puzzle arising from our engagement with tragic works of art assumes that they call for a response that contrasts with that which we tend to exhibit in a normal class of cases. However, the wider the range is of relevantly similar experiences such as those surveyed above, the more dubious is the premise that initially gives rise to the puzzle: our finding value in some experiences in virtue of the negative feelings they evoke is so unlike our other sorts of attitudes and behavior that it requires some distinctive explanation. If we have that response in many contexts outside of our engagement with tragedy, then its paradoxical air is difficult to sustain. We might still want to know what we desire in tragedy, or why it gives us pleasure, but there would be no special problem of tragedy calling for a solution. Indeed, we may contrast those sorts of pursuits in which one takes satisfaction in one's distress with other sorts that do call for a special explanation, such as masochism and pathological practices of self-injury.

Yet there is still something puzzling about what state we are in as audiences for tragedy and similarly antipathetic works of art, whether or not it is also puzzling that we seek to put ourselves in that state. For this is a state in which we both (i) contemplate a work from an external perspective, as an artifact designed through its plot, medium, language, and so on to achieve certain artistic ends; and (ii) imagine the objects, events, and states of affairs of the story as if they were real, or described by a real narrator. What is puzzling is that we are pleased by, value, or desire the particular form and content of the work from an external perspective, yet we feel sadness or some other sort of aversion for what occurs in the work described from an internal perspective. ${ }^{12}$ Thus Peter Lamarque writes, "When Othello kills Desdemona, viewers are appalled by the senselessness and injustice of it, internally and imaginatively. Yet externally, reflecting on the remorseless logic of the drama, they accept that there can be no other outcome." 13 In some sense we don't want Desdemona to die, yet we want Othello, or a performance of the play, to be such that this event occurs in it.

How should we characterize these two attitudes constitutive of our engagement with a tragedy? It is important to properly understand the state in which these two attitudes figure because an account of what responses tragic works of art elicit can help determine which is correct of the many explanations of our desire to occupy that state.

Although affective, evaluative, and conative responses enter into an engagement with tragedy and other aversive arts, I will focus here on just the two kinds of apparently conflicting desires instantiated in the state described above. ${ }^{14}$

By focusing on competing desires, we can better clarify what sort of tension inheres in our enjoyment of tragedy and other distressing forms of art without entering into debates over whether or not emotions can be contrary to desires, or contrary to one another. ${ }^{15}$ Of course, it

\footnotetext{
${ }^{12}$ External features of a narrative--its register and tone, order of exposition, rhythm, and formal devices such as foreshadowing--lie outside the scope of the operator "it is fictional that". However, they can cause us to form desires, beliefs, imaginings, and emotions directed toward what is within the narrative.

${ }^{13}$ Peter Lamarque, Fictional Points of View (Ithaca, NY: Cornell University Press, 1996), 163.

14 That we may characterize the tension characteristic of tragedy in terms not just of emotions, but also desires, has been noted by some recent commentators. See Alex Neill, "Fiction and the Emotions," American Philosophical Quarterly vol 30, no.1 (1993): 1-13.

${ }^{15}$ Of course, many connections can be drawn between emotions and desires. Emotions are sometimes cited as causes or rationalizations of desires. Desires are sometimes cited as causes or rationalizations of emotions. Some kinds of emotions can be characterized as partly constituted
} 
may be disputed that our two desires are mutually inconsistent, but at least we can recognize the prima facie tension in desiring that a performance of King Lear includes Cordelia's death--the value of the work depends on it--and not wanting Cordelia to die.

If we assume that the two apparently competing attitudes operative in our response are desires, how should we identify their objects? ${ }^{16}$ They may be:

(1) alternative fictional states of affairs, e.g., Cordelia dying or not dying; or,

(2) alternative versions of the fictional work, e.g., King Lear; or,

(3) respectively, a fictional state of affairs and the fictional work.

In some cases (1) is a good characterization of the objects of the competing desires evoked by a fiction. In Book 6 of the Iliad Hector prepares to leave Andromache for the battle in which, he acknowledges, he will die. We desire that he submit to her pleas to remain with her and their child, and we desire that he leave for battle, as he insists he must. Both desires cannot be mutually satisfied within the constraints of what the work prescribes for us to imagine. But such a tension does not generate a puzzle, for such an incompatibility between different desires for an imagined state of affairs has a ready parallel in the incompatibility between desires that we may have for things in real life.

If (2) describes our desires, then we both want the work not to be changed, and wish that it were in some significant way different. No doubt, this is a plausible account in some cases. We want Titus Andronicus to be an extravaganza of bloodletting and dismemberment--its artistic power partly resides in its gory marvels--yet, at the same time, we would like the work not to be so unrelentingly violent. Perhaps what it aspires to could be achieved in other ways. Our desires for the work are in conflict, as it cannot satisfy them both. Desiring a work to be other than it is can seem incoherent if one takes every feature of a fictional work to be essential to it. However, we can intelligibly express such a desire in a pro tanto manner: I want Titus to exhibit such violence insofar as it demonstrates the self-destructive fury of revenge, yet I do not want the work to exhibit such violence insofar as it is, or to the extent it becomes, a revolting spectacle. ${ }^{17}$

However, the problem with (2) is that it presents us as not just sometimes properly ambivalent about our desires concerning the content of such works but necessarily ambivalent. It would entail that the proper experience of a tragedy requires that one be torn between a desire that it be performed as it is, and a desire that it be performed without its distressing elements. ${ }^{18}$

by desires--e.g., envy and disappointment respectively reflect the presence and frustration of desires. However, not all emotions lend themselves to such a characterization: admiration for an object does not require a desire to possess it nor does fear entail a desire not to be threatened. ${ }^{16}$ My focus on desires here and throughout is heavily indebted to Gregory Currie, "Tragedy," Analysis vol.70, no.4 (2010): 632-638. (For an earlier, not entirely dissimilar, treatment of the problem, see Kendall Walton, Mimesis as Make-Believe [Cambridge, MA: Harvard University Press, 1990], chapters 5 -7).

${ }^{17}$ Or in the $17^{\text {th }}$-century fashion, we may say we prefer a particular version of the play, e.g., Nahum Tate's 1681 revision of King Lear in which, joyously, Cordelia lives and marries Edgar, and Lear regains his throne.

${ }^{18}$ Currie (2010) notes, "[i]t is not possible, on this account, to experience [Othello] as a tragedy and to want wholeheartedly for it to be a work in which Desdemona dies; one must want it to be a work in which she dies, and want it not to be one," 236. 
Yet while we may occasionally criticize a work for some feature that, if eliminated, would make the work better, this does not seem to be a conceptually mandatory feature of the proper response solicited from us by successful tragic drama.

This leaves us with (3): we desire that the work be such that some state of affairs, S, obtains in it, yet we desire that S not obtain. This doesn't specify what state of affairs we wish were otherwise, but an intuitive answer is that it is the object of our aversive emotions or negative evaluative appraisal. In what follows, I refer to this conjunction of conflicting desires as our internal and external desires for a tragedy or similarly antipathetic art. The modifiers indicate the location of the object of our desires, not the desires themselves.

Not every kind of distressing form of art is naturally described in terms of the desires it evokes. Our engagement with many works is better characterized in terms of our emotions, and only indirectly with reference to the desires that those emotions evince and cause. Tiepolo's fresco of the Sacrifice of Iphigenia shows the moment when, to propitiate Artemis and save his becalmed military fleet, Agamemnon' daughter is to be sacrificed. In visually imagining the priest readying to slit the young girl's neck just as the goddess arrives to restrain him, I feel both apprehension and incipient relief. This naturally suggests that I don't want the priest to act and I do want the goddess to intervene. Yet that is an uncertain indirect attribution of desires based on the much more direct attribution of emotions. In other cases, however, such as in attending to this moment described in Aeschylus's dramatized version of the myth (in which the sacrifice is completed), my desires seem more immediately evident.

Some philosophers argue that we cannot have desires for events or states of affairs that have already taken place, or are otherwise impossible to bring about. ${ }^{19}$ They propose that we speak of wishes for such things when we are apt to refer to desires, or to what we would desire in some counterfactual state of affairs. Others disagree, finding it plausible that one can have such desires as that one had taken a left turn earlier on the drive, or that one were several years younger. ${ }^{20}$ In any case, one can avoid referring to desires concerning how the plot of a work unfolds by referring instead to yet-to-be experienced tokens or instantiations of those works. We want, e.g, the performance we will attend, the version we will read, etc., to be such that some state of affairs, S, obtains in it. Of course, some works of art may be designed to evoke desires whose satisfaction depends on the contingent conditions under which the work is experienced. In Rhythm 0 (1974), Marina Abramović permitted an audience over a six-hour period to manipulate her body using various dangerous and benign items that she supplied (among them flowers, a feather boa, a scalpel, and a loaded pistol). Audience members both wanted Abramović to perform the work such that it could result in her being physically injured--this being a feature on which the work's artistic value supervened--and yet did not want her to be harmed.

The puzzle raised by our conflicting internal and external desires concerning a tragic or

${ }^{19}$ See G. E. M. Anscombe, Intention (Cambridge: Harvard University Press, 1957); and, Anthony Kenny, Action Emotion and Will (London: Routledge and Kegan Paul, 1963).

${ }^{20}$ In many models of the explanation of behavior desires are referred to as encompassing a wide range of "pro attitudes" including wants, wishes, wills, instincts, strivings, urges, yearnings, appetites, and drives. Distinctions among these states may be significant in different explanatory contexts, but the generic use of "desire" casts doubt on there being a clear conceptual distinction between wishes and desires sufficient to deny that we have desires about states of affairs we cannot change. 
otherwise distressing work of art is that, conjoined, they seem to present our engagement with such works as essentially fraught with conflict. Satisfying one desire entails a failure to satisfy the other. Here, even an exemplary work of tragic drama, one possessing the greatest artistic merit, appears always to promise more than it can deliver. Yet, to respond by scaling back one of our desires, e.g., by inducing ourselves not to care whether Cordelia dies, would be to fail to fully appreciate and comprehend a tragedy of great artistic value--one whose design merits both desires. $^{21}$

Thus, it seems that we are oddly conflicted or inconsistent in the desires we have in response to such works. It appears that as audiences we desire something that we also don't desire. If this characterization of our engagement with aversive art forms entails that we are irrational, then we should try to show how it might be mistaken. For it seems implausible that works of art as ubiquitous as these ask us to occupy an irrational state as a condition of their proper appreciation.

Indeed, we need to preserve the idea that an irrational response is possible, without being often or always present, in order to distinguish between those audiences who comprehend and appreciate a work on rational grounds and those who fail to do so, through, for example, imagining as a result of a distorting bias such as wishful thinking that a given fact holds in a fiction when the work prescribes imagining that it does not.

In what follows I address two unsatisfactory attempts to show that, despite appearances, there is no conflict and thus no threat of irrationality. Then I argue that there is, indeed, a genuine conflict but that this need not evince irrationality. Finally, I show how, in instrumental terms, having such conflicting desires in the experience of tragic and other painful works of art can be fully rational.

\section{The two desires do not conflict}

One proposal is that there is no conflict--and thus no conflict instantiating irrationality-between our desires because they are directed at different objects. Our external and internal desires are aspectival: one pertaining to the work as an artifact in the real world and the other to what the work asks us to imagine as true. Any apparent inconsistency here is due only to how we represent and refer to the object of our desires. What we feel is a desire that $p$ with respect to its dimension A and a desire that not- $p$ with respect to its dimension B. The upshot is that I do not desire both that $p$ and that not- $p$.

It is true that desires directed at different aspects of an object need not present any inconsistency. One may desire to drink a glass of whiskey in virtue of its taste but desire not to drink it in virtue of its inebriating effect. However, in such cases the conditions of satisfaction for the two desires are not internally related. A desire for the whiskey's taste and a desire not to be inebriated by it can both be satisfied under some conditions (e.g., one could develop a high tolerance for alcohol). By contrast, in watching a given performance of King Lear, my desire that it be such that Cordelia dies, and my desire that she not die, cannot be mutually satisfied under any conditions.

A related alternative approach is to treat the objects of our desires as distinct, mutually

\footnotetext{
${ }^{21}$ Alex Neill (1993) notes that to attribute such a scaling back of desire to audiences would imply that "what we regard as valuable about certain works of fiction involves wishing that they were other than they are," 10.
} 
exclusive, foci of our attention. ${ }^{22}$ To the extent that appreciation of a tragedy demands that we alternately shift our attention from the artifact-work, its design, staging, meter, and so on, to what we are prompted to imagine by the work, our desires may not come into sufficient closeness for us to register their conflict. Such distinct foci of attention may also result from several inferential steps being required to recognize that the two desires are in conflict. However, in the characterization offered here of our desires, the conflict does not go unnoticed. At the end of the play, as Lear holds Cordelia's lifeless body, we want him to be correct in sensing that she still breathes, yet we recognize that the poignancy of the scene depends on his being deluded.

Finally, one may propose that there is no conflict between our desires if they are of a pro tanto sort. Employing the example above, we may say that one has reason to desire to drink the glass of whiskey insofar as one likes its taste, yet one has reason to desire not to drink it insofar as one wants to remain sober. Appealing to pro tanto reasons brings out the distinct, nonconflicting sets of considerations that, from an agent's perspective, respectively justify his distinct desires. One might thus propose that one has reason to desire that Cordelia live because she is innocent and honest, and reason not to desire that because her death is an essential feature of a deeply moving work. However, this doesn't capture the nature of our desire for Cordelia to survive. We may be caused to form that desire through being shown that she has such admirable qualities, but, once formed, our desire for her to live is not for her qua a bearer of those qualities. Rather our desire is for her as a particular fictional being whose welfare we care about. In this sense, our imagined attachment to characters in fictions can sometimes be formally akin to the attachment we have to real individuals through friendship or love--a kind of concern not appropriately characterized by pro tanto reasons of the above sort. ${ }^{23}$

\section{There are not two desires}

Some theorists argue that what we have identified as a conflict of desires over a work of tragedy is only apparent, for one of those putative desires is only an imaginative counterpart of a real desire, an $i$-desire that shares some, but not all, of a real desire's functional roles. ${ }^{24}$ Their proposal is that such $\mathrm{i}$-desires are related to genuine desires in a way analogous to how imaginings are related to beliefs. Desires and beliefs have as their content some proposition about the real world; i-desires and imaginings have as their contents propositions that are true in a fiction, pretense, or other form of make-believe.

Employing the concept of an i-desire in identifying our attitudes toward a tragedy, we may say that we have a genuine, real world, desire that King Lear be such that it represents the

\footnotetext{
${ }^{22}$ See the attention-based theory of desire in Tim Scanlon, What We Owe to Each Other (Cambridge, MA: Harvard University Press, 1998).

${ }^{23}$ On our attachment to characters in tragic works see Catherine Wilson, "Grief and the Poet," British Journal of Aesthetics vol. 53, no.1 (2013): 77-91; and Jonathan Gilmore, "Grief and Belief," British Journal of Aesthetics vol. 53, no.1 (2013): 103-107.

${ }^{24}$ Although it is not clear that the concept is always employed in the same way, such imaginative counterparts of desires are variously identified as i-desires [Tyler Doggett and Andy Egan, "How We Feel About Terrible, Non-Existent Mafiosi," Philosophy and Phenomenological Research vol. 84, no.2 (2012): 277-306)]; desire-like imaginings [Gregory Currie and Ian Ravenscroft, Recreative Minds: Imagination In Philosophy and Psychology (Oxford: Oxford University Press, 2003)]; and desires held off-line [Goldman, Alvin, Simulating Minds: The Philosophy, Psychology, and Neuroscience of Mindreading (Oxford: Oxford University Press, 2006)].
} 
king's descent in status and decline into madness, yet we only imaginatively, or in imagination, desire that he not undergo such loss.

One reason for denying that I have an actual desire that Lear not be harmed is that my behavior does not exhibit the motivational dimensions that tend to accompany real desires. I might turn away from the stage, or close the book that I'm reading, but these reflect desires to end my experience of the fiction, not to act on my desire for some state of affairs in it.

It isn't obvious that we exhibit none of the markers of being motivated to act on desires when we know their contents are fictional. Watching some harrowing event concerning a protagonist, we do not rush onstage to intervene. But we may exhibit other tendencies to act, by grimacing, recoiling in our seat, or, less automatically, looking for a place within the presented scene--on stage or film--where the character can seek refuge. Or we may try to recall facts in the story, or consider facts that the story permits us to import into it, that would help her: the presence of a weapon, vulnerability in an attacker, some strategy to turn the tables on the antagonist.

Nonetheless, such behavior can plausibly be classified as merely part of the activity of understanding the content of the fiction, trying to discover what is true in it. Also, if we do continue to notice, e.g., the ways in which in a fiction a character could escape her death, even though we know we are meant to imagine that she cannot, our cognitive behavior would appear less motivated to affect those fictional events than to identify real-world defects in the construction of the plot.

A stronger rejoinder to the "no motivation" objection to the genuineness of our desires for what is solely make-believe, is that desires tend to motivate only in connection with relevant beliefs, and no such belief, e.g., that these are circumstances that one can affect, is present in one's engagement with fictions. ${ }^{25}$

Another reason offered for denying the genuineness of our desire for what is internal to a tragedy, is that, if genuine, it would impose an odd disappointment on audiences. We are disappointed over either the shape of the work, or what happens in the work. For the proponent of i-desires, describing our experience of tragedies as ultimately disappointing seems counterintuitive. If, however, one of those putative desires is only an i-desire, then its not being satisfied in the fiction generates no real disappointment, only a feeling of, e.g., sadness, that appropriately appraises what happens in the fiction.

It is not clear here where the burden of proof lies. It is prima facie plausible that one can regret, bemoan, or express disappointment over some event that occurred in a work of fiction. ${ }^{26}$ Indeed, that readers of a fiction sometimes don't cease to feel sadness for the death of a novel's protagonist even after they close the book suggests that one's desire for some imagined state of affairs can be disappointed. If one experienced no feeling evincing disappointment that, say, Anna Karenina kills herself, this would cast doubt on whether one had either a desire or an $i$ desire for her well-being in reading the novel. Of course, the proponent of i-desires may suggest that what the reader feels after finishing the work is only an imaginative counterpart of genuine

\footnotetext{
${ }^{25}$ See Peter Caruthers, "Why Pretend?" in The Architecture of the Imagination, ed., Shaun Nichols (Oxford: Oxford University Press, 2006), 99.
}

${ }^{26}$ George Eliot notes this at the end of Middlemarch: "Who can quit young lives after being long in company with them, and not desire to know what befell them in their after-years" (New York: Oxford World Classics. 1998), 779. 
disappointment, but then the premise that we are not in a state in which we experience the phenomenology of disappointment (real or imagined) is much weaker. What might explain the apparent counter-intuitiveness of attributing disappointment to audiences is the mistaken inference that this implies that audiences feel that the work has fallen short of some standard of artistic value. $^{27}$ That need not be so, for the disappointment at issue here is over a state of affairs that one imagines to have obtained, not over the real-world degree to which the work realizes its artistic ends. Indeed such disappointment may reflect the work's power in generating such desires for what is only fictional.

\section{There is a conflict between two desires but not an irrational one}

Both approaches represented in 1. and 2. assume that audiences have all-thingsconsidered desires of the internal and external kind for some state of affairs in a fiction, and that, if those desires conflict, having them is irrational. They try to block that threat of irrationality by demonstrating that there is no conflict. However, a different tactic is to acknowledge that there is a conflict in an audience's all-things-considered desires, but deny the assumption that having such conflicting desires is always irrational: to desire, in reading Anna Karenina, that the novel portrays Anna's death seems to be in a serious tension with the desire that Anna not die. Yet it is difficult to identify any norm that would render having such a conjunction of desires systematically irrational.

Let us first consider those desires in light of norms of theoretical rationality--constraints governing a rational person's formation, maintenance, transitions among, and relinquishing of her beliefs. It might seem, rather, that norms of practical rationality are most relevant here. However, to the extent that such practical norms apply to one's desires, it is qua desire's role in explaining one's motivation to form intentions or to act. In the case of our desires for tragedy, no such intentions or actions are present that could serve as data for the assessment of the desires. So here I will primarily consider norms of theoretical rationality. In the next section, however, I will show one way in which our desires for tragic works can be assessed by a norm of a practical, specifically instrumental, kind.

A plausible rational constraint on our beliefs is that we ought not fully to adopt or endorse two inconsistent beliefs when we recognize that they cannot both be true. A less stringent rational constraint is that, faced with a salient inconsistency between two of my beliefs, I need not give either or both up, but ought to assign a lesser degree of credibility to each, or give them a less-than-full endorsement in any role they play in my inferences.

Is there any comparable consistency requirement on desires? We may have inconsistent desires because they are based on inconsistent beliefs, yet this points only to a potential defect in theoretical rationality, not in the rationality of the desires. ${ }^{28}$ Alternatively, we may have inconsistent desires where their conflict is due to their conditions of satisfaction: they cannot

\footnotetext{
${ }^{27}$ Egan and Doggett (2012) write, "[the deaths of Romeo and Juliet] are an occasion for a distinctive sort of saddened affect, but they are not an occasion for any kind of aesthetic disappointment- not even aesthetic disappointment that's more than compensated for by aesthetic benefits that couldn't otherwise be achieved," 282.

${ }^{28}$ Thus, some accounts of the rationality of desires do not address them qua desires but for the beliefs or epistemic processes upon which the formation and holding of the desires depends. See Richard Brandt, A Theory of the Good and the Right (Oxford: Clarendon Press, 1979).
} 
both be satisfied in this world (a contingent inconsistency), or cannot both be satisfied in any world (a necessary inconsistency). But if having either kind of inconsistent desires can count against one's rationality, it would not be for the reasons that contrary beliefs can be irrational, for the two kinds of states have different "directions of fit." To knowingly hold inconsistent beliefs is to represent the world as existing in two incompatible forms, and thus betray some defect in how one acquired or reasons with those beliefs. By contrast, knowingly having inconsistent desires need not express a defect in how they are acquired or held. For their inconsistency may be solely due to fact that our world, or any world, does not allow their mutual satisfaction.

Another rational constraint on our beliefs pertains to their coherence. If I believe $p$ and know that $p$ entails $q$, I rationally should believe $q$ (or at least not affirm its negation, given that many facts that we are indifferent to are entailed by our beliefs). An analogous principle might seem to hold for desires. ${ }^{29}$ However, on many occasions one can desire $p$ and know that if $p$ then $q$ without desiring $q$. Indeed, one might desire both $p$ and not- $q$. I desire to play loud music late at night, even though I know that this will wake my neighbors. Yet I don't want to wake my neighbors.

A different candidate for a norm of coherence among desires is that, if I know that $p$ is necessary to realize my desire that $q$, I ought to desire that $p$. If, e.g., I know that attending cooking school is necessary for me to realize my desire to become a chef, I ought to have at least a defeasible desire to attend cooking school. However, this principle admits of many exceptions. Consider a case somewhat analogous to our two responses to tragedy. I have a standing desire for my game of tennis that it be highly competitive and close-scoring, for it's less fun when one player dominates the other. Yet even when, on occasion, preserving a close score depends on my opponent winning the point, I may rationally never have the desire, not even a defeasible one, that he succeed. I want the game to be even and competitive, yet in playing I fully want every point to go my way. ${ }^{30}$

Finally, in rationally forming our beliefs, we rely on standard evidentiary sources such as testimony, perception, memory, inductive and deductive inference, and our affective responses. When all goes well, these sources provide the right sorts of reasons for our beliefs: specifically, reasons that justify or serve as a warrant for what we believe. Thus, it is irrational to form a belief on the basis of a reason that doesn't speak to evidence in favor of its truth, such as that it would be good if the belief were true. Some philosophers argue that, analogously, we may criticize a desire for the reasons that, from the agent's point of view, are taken to warrant it. ${ }^{31}$ It counts against the rationality of someone's desire to bet on horses if it's based on the belief that

\footnotetext{
${ }^{29}$ Egan and Doggett (2012) write, "having the desire about the fictional character (at least) rationally requires that one have the corresponding desire about the content of the fiction, since as you well know, the only way for the fictional character to have the property that we desire him to have is for the content of the fiction to make it so," 284-285.

${ }^{30}$ Some philosophers argue that desires "aim for the good." Whether this is adopted as conceptual constraint or a norm of rationality, both internal and external desires for tragedy would pass muster. See, for instance, Anscombe (1957). But for contrary arguments, see Michael Stocker, "Desiring the Bad - An Essay in Moral Psychology," The Journal of Philosophy 76, no. 12 (1979): 738-53; and David Velleman, "The Guise of the Good," Nous 26, no. 1 (1992): 3-26.

${ }^{31}$ See Jonathan Dancy," Practical Reality (Oxford: Clarendon Press, 2000): “[W]e can in general understand desire as a response to a perceived reason," p. 38.
} 
this is a reliable method of saving for retirement. This is a criticism of a desire as both theoretically irrational, in depending on a faulty belief, and practically irrational, in not contributing to the satisfaction of the person's more primary desires. However, neither of these forms of criticism applies to the competing desires operative in responses to tragic drama. Typically, in responding to a work of sufficient artistic merit, each desire is justified by the reasons one would have for forming them, and neither desire tends to conflict with one's primary interests. Of course, only one of these desires is satisfied, raising the question of whether it is rational to regularly form a desire that one knows will be frustrated. In the next section I take up the rationality of the higher-order desire to have this experience, characteristic of our engagement with tragedy, of such only partially fulfilled lower-order desires.

\section{The conflict between our two desires is rational in light of a third desire}

We see from the above discussion that in none of the familiar terms in which we speak of theoretic irrationality do the desires operative in the appreciation of fiction appear systematically irrational. However, while one's worry over a putative irrationality in our conflicting desires may have abated, one might still wonder if such desires have any rational standing at all. For one may conclude from the discussion above that our desire for a given state of affairs in a fiction is merely arational, not susceptible to rational justification or criticism. In this way, desires about the contents of a fiction would be comparable to other mental states that have representational content, such as dreams, but which are not appropriate objects of rational appraisal. Yet, as noted earlier, it seems that a commitment to the categorical rational status of such desires is entailed by the fact that sometimes the desires audiences have seem to fail to respond appropriately to a work. We may rationally criticize one's cognitive response to a work in asking whether what one imagines conforms to what the work prescribes one to imagine. And we may rationally criticize an affective response to a work in asking whether it is true in the work, or is part of the fiction, that the emotion's object has the qualities that justify the emotion. ${ }^{32}$ But how might we show that our conative responses to a tragedy are subject to rational evaluation?

We may begin by noting that we criticize a desire felt for some feature of a fiction if it betrays a cognitive misunderstanding of what is true in the fiction. I may want Iago to succeed in his sinister schemes, say, because I identify with his envy of Cassio, or his resentment over not being promoted by Othello. Yet the drama does not present the success of Iago's plans as meriting such a desire. My desire thus presents those plans in the fiction as having evaluative qualities contrary to what in the fiction they exhibit. ${ }^{33}$ Of course, in a work in which there is greater ambiguity in what audiences are meant to desire, or an artistic failure in motivating such desires, such criticism may be unfounded. The important point is that our desires for some fictional state of affairs may be appropriately evaluated for their fit with the evaluative qualities that the work presents the state of affairs as exemplifying. However, even when our desire for some state of affairs in a tragedy is shown to be rational in this light, it is still in conflict with the

\footnotetext{
${ }^{32}$ See Jonathan Gilmore, “Aptness of Emotions for Fictions and Imaginings," Pacific Philosophical Quarterly vol. 92, no.4 (2011): 468-489.

${ }^{33}$ This kind of criticism of such a desire would fit with those accounts in which desires are construed as truth-apt in virtue of presenting a state of affairs as good. In this view, a desire that $p$ is an impression or registration in some way that it would be good if $p$. See Dennis Stampe, "The Authority of Desire," Philosophical Review 96 (1987): 335-81.
} 
external desire we have about the fiction, which we presume raises no special question of rationality. Even though each desire can be individually justified, their conjunction remains without a rational justification.

I propose that having such conflicting desires is rational in an instrumental sense of a peculiar kind. ${ }^{34}$ A rational second-order desire of ours is satisfied through having the two firstorder desires. That second-order desire is for the realization of one or more of the goods--such as pleasure--featured in the solutions to the paradox of tragedy surveyed earlier. The reasons that justify one's motivation to pursue those goods also serve to justify one's having the internal and external conflicting desires constitutive of the experience that realizes those goods. In other words, the rationality of the end of satisfying the higher-order desire renders rational the joint possession of the lower-order desires. Let me try to justify this claim.

Sometimes when a person has one desire that has as its object the acquisition of another desire, the person's reasons for the former are also reasons for the latter. Suppose I desire to improve my health but believe that I can do this only if I form the desire to exercise. There, improving my health can be my reason both for desiring to exercise and for desiring to acquire that desire. However, in other cases, there is no such "transitivity" of justification. A scientist studying caffeine addiction might choose to develop a desire to drink several cups of coffee each day. There, her reason for desiring the coffee--say, its stimulating effect--would not be identical to her reason for desiring to have that desire. ${ }^{35}$

Our experience of tragic and other distressing works of art can instantiate a structure of desires of the second kind. The answer to what justifies our lower-order desires is distinct from the answer to what justifies our higher-order desire to form those lower-order desires. We have a desire to form both (i) the (painfully frustrated) desire that Lear retain or recover his standing, and (ii) the (happily satisfied) desire that King Lear be performed such that, in the fiction, Lear loses his kingdom and identity. Each desire is explained and justified by a different reason: We want Lear not to lose his kingdom because he is the victim of treachery and we pity his decline and loss of self. But we also want the performance to include these events because Lear struggling to hold on to his kingdom and his identity is a source of the work's great pathos. And we desire to form and have those two desires because, by virtue of experiencing the frustration of the first and the satisfaction of the second, we garner one or more of the benefits proposed in those resolutions to the paradox of tragedy canvassed earlier. So there are three desires constitutive of our conative engagement with tragedy:

(1) a desire that a work be such that something, S, occurs in it;

(2) a desire that S not occur; and,

(3) a desire that one have both (1) and (2)

My claim is that we are instrumentally rational in forming and having the conflicting desires (1) and (2) because having both those desires is necessary for the satisfaction of desire (3).

${ }^{34}$ I am indebted here to Richard Joyce's instrumental account of the rationality of fictiondirected emotions generally. See his "Rational Fear of Monsters," British Journal of Aesthetics 40, no. 2 (2000): 209-224.

35 This point was first made by Harry Frankfurt in "Freedom of the Will and the Concept of a Person," Journal of Philosophy 68 (1971): 5-20. 
One might object that having a desire is not an action and thus not the sort of thing that can be justified by the instrumental role it plays in achieving some rationally desired end. Digestion and respiration are normally necessary for one to act on any given intention, yet even if acting thus is perfectly rational, this does not make digestion and respiration rational. However, the proper object of rational assessment is our acting so as to form our lower-order desires. We do that in choosing to experience a tragic or otherwise painful work of art when we can predict the desires or kinds of desires that it will provoke in us. We decide, for example, to attend a tragic drama instead of a light comedy; read an elegy rather than a satire, or see a film by a director known for works of unrelenting bleakness. In each case, we act on our desire to form desires central to the experiences of these works. We don't, that is, want those things prior to experiencing the works. And sometimes, after forming these desires, one no longer wants to feel them. Contemplating the inevitable frustration of one's wish for a happy ending, one closes the book or stops the film, intending to eliminate the conditions under which the desires are sustained.

Of course, many of the desires that we form in engagement with a work of art are not sufficiently predictable so as to be assessed in terms of instrumental rationality. Yet the fact that complexes of desires, broadly described, are respectively indexed to different genres and other categories of art, as well as to particular artists, media, and venues, suggests that in some cases these desires are, indeed, knowingly acquired or formed when we choose to attend, read, see, etc., the work that elicit them.

This proposal does not assume that any given mental state can be rendered rational in virtue of instrumentally serving the satisfaction of some bona fide rational desire. The costs of forming, having, and satisfying the lower-order instrumental desires may outweigh the benefit of satisfying the higher-order final desire. Indeed, we should notice that our higher-order desire for the experience of tragedy does not always justify the formation of the two lower-order ones. The rationalization can fail. A work can be so disconcerting that our desire to experience it for the sake of, e.g., a compensating pleasure is not warranted. This is rarely the case in relation to great works of painful art, in that their greatness consists in part in offering us reason to undergo the pain that a proper comprehension of them can elicit. However, we must allow that sometimes the satisfaction of the higher-order desire to experience such a work isn't worth the disquiet that its activation of lower-order desires results in. ${ }^{36}$

In distinguishing the structure of these three types of desires, we can identify an important condition of a tragedy's success qua tragedy. ${ }^{37}$ It is that the work generates precisely the conjunction of the first-order desires. If we have an external desire that a tragedy be performed such that its heroine dies and yet no internal desire that she not die, this would signify a failure of the work to elicit our concern for that fictional individual. If we have the desire that she not die but no preference over whether the work is such that her death occurs in it, this would mean that we care about what merits our desires for what we imagine to exist, but not for the work's artistic ends in eliciting those desires. In such circumstances, we sometimes judge a work

\footnotetext{
${ }^{36}$ In his Preface to Shakespeare's plays (1765), Samuel Johnson notes, "I was many years ago so shocked by Cordelia's death, that I know not whether I ever endured to read again the last scenes of the play till I undertook to revise them as an editor."

${ }^{37}$ I refer here not to a condition only of the genre--conventions of which have included, e.g., that its subject be noble and its style elevated--but of works that we seek knowing of the aversive responses they elicit.
} 
as sentimental, manipulative or meretricious in virtue of successfully evoking and frustrating our desires for a fictional character's welfare without offering us sufficient artistic returns to justify our having formed that frustrated desire in the first place. Our engagement with tragic works generally is rationally justified by the values that solutions to the paradox of tragedy attribute to such works. However, this does not eliminate the risk one takes on in the experience of any particular work: one may develop a desire that one need not have formed, and that, once formed, one wishes one didn't have. 